\title{
Application of Knowledge Based Systems for Child Performance Analysis in an Online Montessori Management System
}

\author{
Siti Hajar Khairuddin, Norlia Mustaffa, Wahidah Husain, Faten Damanhoori \\ School of Computer Sciences, Universiti Sains Malaysia, USM, Penang, 11800, Malaysia \\ E-mail: shk_tm009@student.usm.my,norlia@cs.usm.my,wahidah@cs.usm.my,faten@cs.usm.my
}

\begin{abstract}
This paper focuses on the application of knowledge based systems for child performance analysis in an online Montessori module. Using knowledge based techniques, the system generates an automatic analysis based on the teacher's answers to a variety of questions about a child's performance of a specific Montessori activity. The questions were created through a study of the criteria used to assess the level of a child's performance and achievement. This prototype is designed as a proof-of-concept, to show how the knowledge base technique could be applied. To design the prototype, we conducted literature reviews on the delivery of Montessori methods and the knowledge base technique, and compared rule -based and case -based reasoning. We selected rule-based reasoning for the concept prototype since it is suitable for Montessori activities which are well defined and easy to acquire.
\end{abstract}

Keywords - Montessori method; Child performance; knowledge based technique; rule based reasoning.

\section{INTRODUCTION}

This research explores the application of knowledge based techniques to child performance analysis in one module of an online Montessori management system called Easy Montessori Manager. Easy Montessori Manager is a portal dedicated to preschools which use the Montessori approach in their teaching. One of the modules in this portal is designed to generate an analysis of a child's performance. The analysis is given in the form of statements drawn from the Montessori handbook, other Montessori manuals, and experienced principals and teachers. The objectives of this research are 1) to explore the use of a knowledge based system to analyze a child's performance in an online Montessori module, and 2) to test the use of rule-based reasoning to generate an analysis using knowledge based techniques. The purpose is to assist in the design of a concept prototype.

\section{BACKGROUND}

\section{A. Knowledge Based System}

A Knowledge Based System (KBS), also called an expert system, is one which enables the storage, representation, processing and retrieval of domain-specific knowledge. It is a subset of the field of Artificial Intelligence (AI), which is focused on making intelligent machines, such as intelligent computer programs. AI and KBS have the same goal: using the computer to understand or mimic human intelligence [1].
A KBS contains both tacit and explicit knowledge about a domain, usually a domain which requires expert, rather than common-sense knowledge [2]. According to Mockler and Dologite [3], knowledge bases are collections of expert knowledge.

Thus, a KBS is a computerized system which attempts to replicate specific human expert intelligence. For example, the system can make decisions, offer recommendations, answer questions and perform tasks just like an expert human advisor [3]. It can also add to its information by questioning the users of the system.

Generally, the structure of a KBS has three components: the knowledge base, an inference engine, and the user interface [2]. The knowledge base, as stated above, contains data relating to a specific situation or decision domain. It can also be described as a database with the addition of some rules used to interpret and apply the data stored in it. The inference engine, also called inferential reasoning capability [3], mimics the way an expert thinks by directing and controlling the use of knowledge to derive one or more solutions to problems [2]. The user interface serves as the link between the KBS and the user.

\section{B. Rule-based vs Case-based Reasoning}

Rule-based reasoning, or the IF-THEN rule, is the most common way for a KBS to represent knowledge. It can be modified to meet changing needs, can be easily updated and is able to ask users questions to help it solve their problems [3]. In a rule-based system, the knowledge base consists of 
data items or facts and the rules specify the relationships to be used to interpret the data items [2].

The inference engine controls the reasoning process and the manipulation of data in the knowledge base. It can be either data-driven (forward chaining) or goal-driven (backward chaining) [3]. In forward chaining the reasoning begins by examining the IF clauses and searches for solutions by working from data toward the solution. Backward chaining starts with one or more possible goals and works backward to see if there is data available that will support any of the consequences.

A rule-based reasoning system handles problems using a well defined knowledge base which contains the rules. This approach is regarded as better understood and more precise, and is very useful in guiding the user to a given goal. It makes use of existing domain theory since it is already well defined. For this reason, rule-based reasoning is not practical in a poorly-understood knowledge domain [4], or in one which cannot be easily represented by simple IF-THEN rules.

Case-based reasoning is most appropriate for an experience-rich domain. It draws inferences about a new case by comparing it with previous cases stored in the system. Unlike rule-based reasoning, this approach is suitable for a problem domain that is difficult to represent in rules [4]. The advantage of this approach is that the knowledge base is relatively easy to set up since cases (examples of problems) are usually readily available along with their associated solutions. It is also suitable for problem domains that are not easily understood, and is easily expanded by adding new cases to the knowledge base.

The main disadvantage of case-based reasoning is that it is not always easy to retrieve cases that are similar to the current problem. It uses a "similarity measure" which associates a numerical value with each case to indicate level of similarity. It is not always easy, or even possible, to find cases with the appropriate high values.

Rule-based reasoning was chosen for this study because the knowledge domain of Montessori is well defined. It has been separated and categorized by its methods, with each method having its own theory, material and philosophy. The main advantage is that Montessori knowledge provides goals and purposes for each activity. Furthermore, a rule-based system is easy to update to meet changing needs, since research on the Montessori method is an ongoing effort. It is also suitable because of its capability to ask questions to facilitate problem-solving.

\section{Method of AnALyzing ChILDREN'S PeRformance IN MONTESSORI PRESCHOOLS}

Assessment and performance analysis of young children such as preschool students are not easy. One of the difficulties is that child development involves more than one area, including physical, social, emotional, and academic. Children's development is also uneven and rapid. Furthermore, their performance cannot be assessed through traditional standardized tests since they have limited reading and writing capabilities. Children of preschool age are better at showing their progress rather than writing or talking about it [5].

Several techniques have been used by preschools to evaluate and analyze children's performance. The techniques can be formal or informal, and the method of information collection depends on how the administration designs it. One commonly used technique is mastery of tasks, whereby the teachers will ask the child to perform a few tasks and demonstrate one or more skills; they then record the child's level of mastery on checklists, questionnaires or rating scales. The teacher's assessment is usually based on their observations of the child while he performs the activities [5]. The performance portfolio is another well-known approach, whereby the teacher will gather examples of all the child's work and activities and record an evaluation based on these works. Some preschools keep observation records which can be either formal or informal.

In Montessori schools, the ability of each child is respected. There are no examinations and the child's work is not returned with corrections or red marks because their works are respected as it is. Evaluations are made through extensive observation and each child's activities are based on his or her own capabilities and interests rather than being assigned by the teacher. Montessori teachers do not provide any sort of grades, rewards or punishment. Assessments are usually done through portfolios and observations. To test whether the system is working, the teacher relies on the child's accomplishments, behaviours, maturity, level of works and many other elements [6]. The child's performance is discussed with parents in a formal or informal way, as necessary [7].

Because the Montessori philosophy does not allow grading or testing of children to evaluate them, Montessori preschools usually do not have standard guidelines on how to evaluate and record the children's performances [8]. Thus, the administration of a Montessori school usually relies on the experience, training and academic knowledge of the teachers and principals to come up with techniques for evaluating the children's performance.

It is common for Montessori preschools to develop their own charts or checklists that indicate work that should have, or has, been completed by the child [8]. Some charts record whether or not the child has mastered the activity. Teachers also usually collect samples of the child's work, such as writing, art projects, drawings or even photographs. Most preschools also maintain observation notes that summarize the child's progress [8].

Although the Montessori method is practiced by many countries with many different cultures, several traits commonly show up in Montessori trained children. Bourne [8] identified eight characteristics in the development and performance of a Montessori trained child: independence, confidence, self-discipline, intrinsic motivation, ability to handle external authority, academic achievement, spiritual awareness and responsible citizenship. All these characteristics will not necessarily be displayed by a child at one time, but by looking for glimpses of these characteristics, a teacher can find evidence that the child is progressing in each area. The progress can be fast or slow depending on each child's capabilities.

Most Montessori preschools provide their own progress reports after collecting the performance records. Each school designs its own according to its preferences. To respect the Montessori philosophy, there are also no grades in the progress reports. Teachers are advised to create a rubric 
against which to measure the child's progress [6]. One example of a rubric performance key might be good, very good, developing skills or needs help. The sections can be divided according to the type of Montessori method. Based on their observations, a teacher can indicate a child's performance by filling in the rubric performance keys, as well as in narrative form, e.g. "this child shows confidence in performing this activity". The performance analysis should always refer back to the goals or skills that the children are expected to achieve for each method or activity [6].

\section{IV.METHODOLOGY}

For the prototype, we looked at both the phases of the KBS development life cycle and the steps in the development of the KBS prototype.

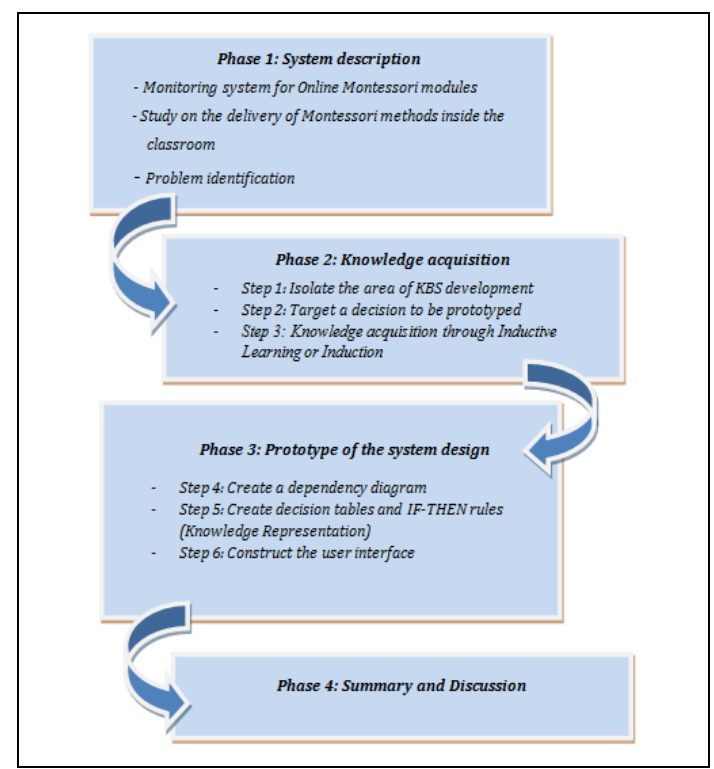

Fig 1: Research Methodology

\section{A. Phase 1: System Description}

The elements of the monitoring system for Online Montessori modules are shown in Figure 2.

The steps for the monitoring system are as follows:

1. The principal or teacher selects a child from the system's list of names or classrooms.

2. The principal or teacher selects the Montessori area to be assessed by choosing Motor education, Sensorial education, Language or Other.

3. The principal or teacher views the guidelines provided for each method in the system.

4. With the help of the KBS, an analysis of the child's performance is generated based on which modules have been completed, the types of method completed and the number of modules completed. The resulting analysis describes the child's progress at his or her school.

\section{B. Phase 2: Knowledge Acquisition}

Knowledge Acquisition goes through three steps to obtain the necessary knowledge base for the prototype.

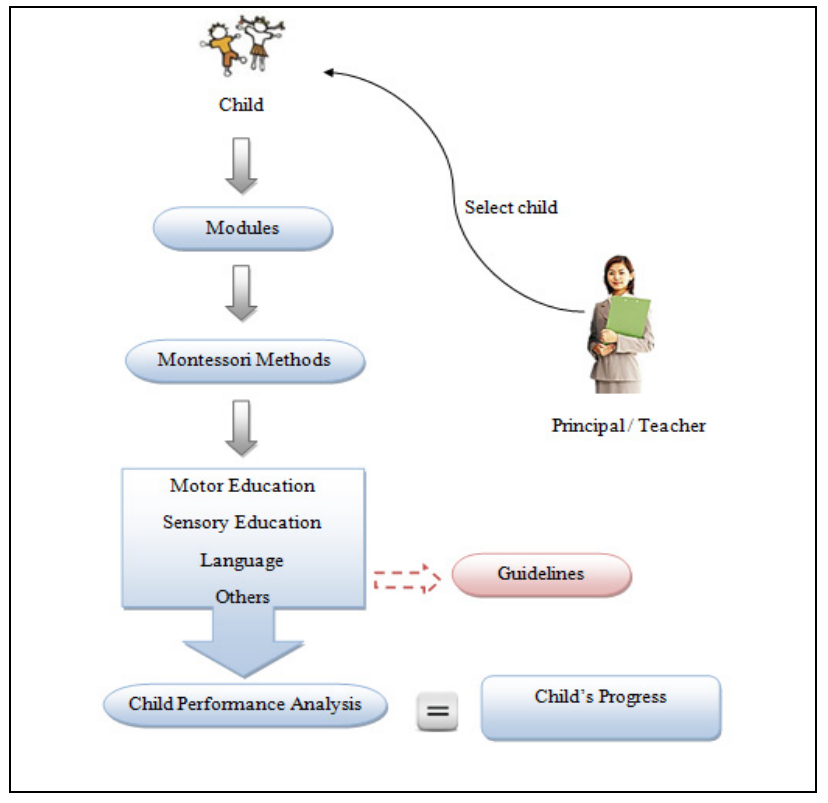

Fig 2: Elements in Monitoring System of the Online Montessori System

Step 1: Isolate the area of KBS development.

Figure 3 shows the elements in the proposed online system, Easy Montessori Manager. It has two parts: the Online Montessori Module and the Management Features. The Management Features are similar to other school management systems available online. The Online Montessori Module provides the Montessori methods and guidelines, the child's performance according to the modules accomplished and the performance analysis. The focus of this study for the prototyping of the KBS concept is the Montessori analysis (shown in red). The factors involved in creating the analysis are the Montessori method, the apparatus used and the theory behind each method.

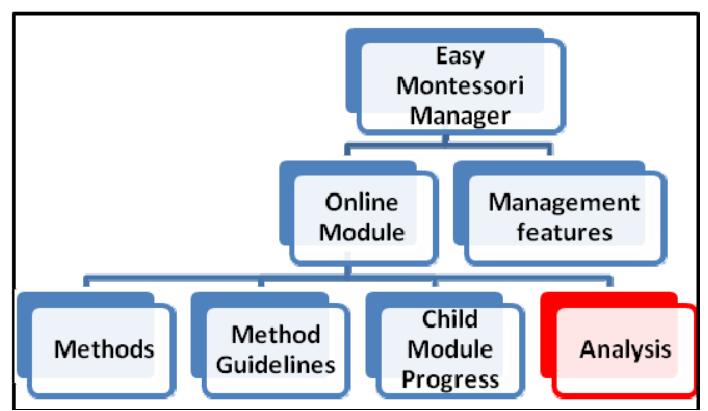

Fig 3: Elements of Easy Montessori Manager

Step 2: Target a decision to be prototyped

The next step is to define the problem or decision to be modeled in the KBS application. The factors involved are summarized in Figure 4.

Step 3: Knowledge acquisition through Inductive Learning or Induction

Knowledge acquisition using an automated tool is a form of inductive learning or induction. For inductive knowledge acquisition, the system must already have an existing database which can be converted into a set of production rules. Thus, the database must have the necessary examples 
which provide the solution to a problem. For the prototype, we focus on one area of the Montessori method: Sensory education.

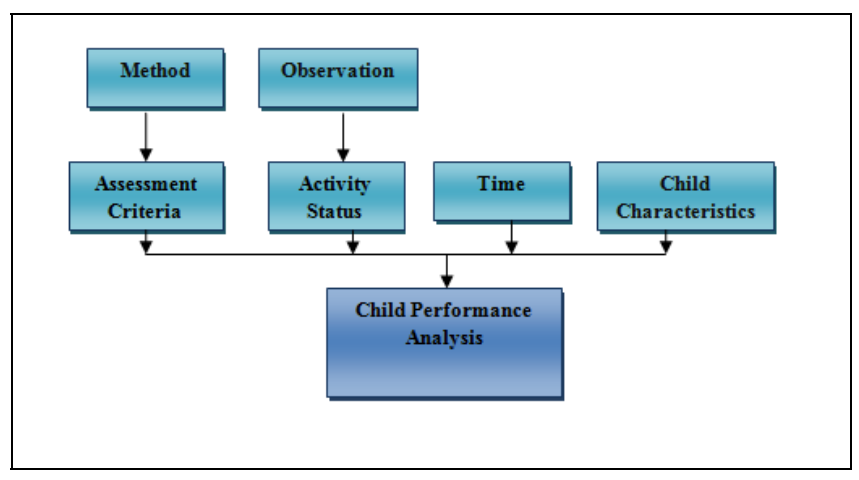

Fig 4: Factors Involved in the Montessori Analysis

Table 1 shows Bourne's eight characteristics of Montessori children, which they are expected to develop as they master the Montessori methods. The criteria are based on the Montessori handbook as well as on the literature review. They were then verified by an experienced Montessori principal. These criteria form the main assessment of each child, besides the other criteria specific to each Montessori method. The symbols were assigned to make it convenient when the criteria are transferred into a dependency diagram in the next step.

TABLE 1

CHARACTERISTICS OF MONTESSORI CHILDREN

\begin{tabular}{|c|c|c|}
\hline Symbol & Characteristic & Criteria \\
\hline A & Independence & $\begin{array}{l}\text { - Child works by himself } \\
\text { - Child does not need assistance }\end{array}$ \\
\hline B & Confidence & $\begin{array}{l}\text { - Child knows how to find help } \\
\text { when needed } \\
\text { - Child wants to do new things } \\
\text { and be adventurous }\end{array}$ \\
\hline $\mathrm{C}$ & Self Discipline & $\begin{array}{l}\text { - Child makes the right choice } \\
\text { without teacher intervention }\end{array}$ \\
\hline $\mathrm{D}$ & Intrinsic Motivation & $\begin{array}{l}\text { - Child instinctively knows what } \\
\text { to do }\end{array}$ \\
\hline $\mathrm{E}$ & $\begin{array}{l}\text { Ability to Handle } \\
\text { External Authority }\end{array}$ & $\begin{array}{l}\text { - Child respects teachers, } \\
\text { materials and other members of } \\
\text { the class }\end{array}$ \\
\hline $\mathrm{F}$ & $\begin{array}{c}\text { Academic } \\
\text { Achievement }\end{array}$ & - Child completes his tasks \\
\hline G & Spiritual Awareness & $\begin{array}{l}\text { - Child appreciates spiritual } \\
\text { issues }\end{array}$ \\
\hline $\mathrm{H}$ & $\begin{array}{l}\text { Responsible } \\
\text { Citizenship }\end{array}$ & $\begin{array}{l}\text { - Child is interested in current } \\
\text { events }\end{array}$ \\
\hline
\end{tabular}

\section{Phase 3: Prototype the System Design}

\section{Step 4: Create a Dependency Diagram}

In Step 4, the factors in creating the analysis are transformed into a dependency diagram as shown in Figure 5. The dependency diagram shows the relationships or dependencies among the critical factors, input questions, values, rules and recommendations made by the KBS [3].

In Figure 5, the boxes represent the critical factors identified in Step 2 above (method, assessment criteria, observation, activity status, time and number of criteria).
The triangles next to the boxes identify the collection of KBS rule sets. The final triangle at the right side of the diagram links all the input lines at the concluding recommendation box. Time and number of criteria feed directly into the final recommendation. The items that influence the outcome of the critical factors are called 'variables' [3]. The variables in the dependency diagram are method, observation status, time and number of criteria. Below each variable are the possible values. Possible values are also given for the critical factors and the recommendation box.

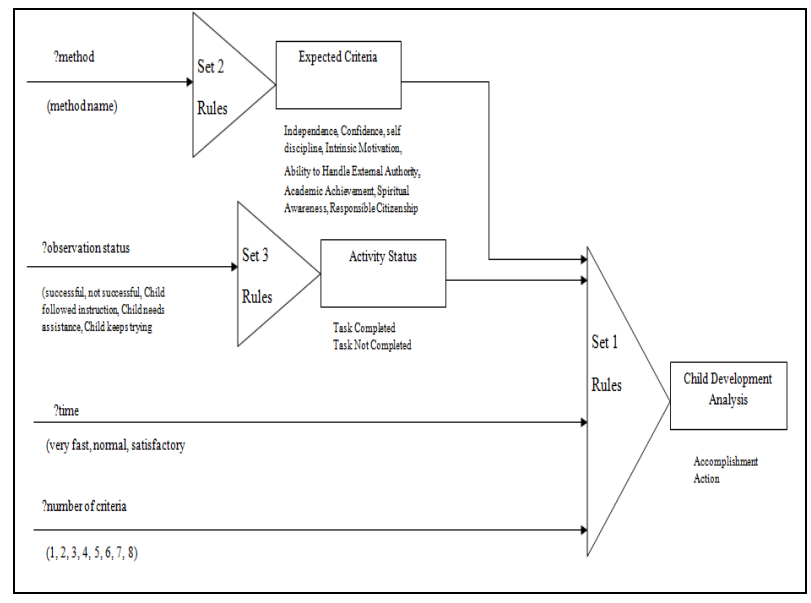

Fig 5: Dependency Diagram of the Factors of Montessori Analysis

A decision table is created for each triangle in the dependency diagram. Creating a decision table is the final modeling step before producing the rules. The first step in developing a decision table is to plan the number of rows necessary for the table [3] by listing the conditions from the dependency diagram which are directed to and from the triangles. Figure 5 shows that the conditions consist of method, expected criteria, activity status, time and number of criteria. Next, the value for each condition is listed. The planning table for the complete decision table for the final rule set (Set 1 in the dependency diagram) is given in Table 2 , and shows that the decision table will need to have 18 rows, one for each value of each condition. The full decision table for Set 1 Rules is shown in Table 3.

Table 2: Planning Table for Set 1 Decision Table

\begin{tabular}{|l|l|}
\hline Conditions & Number of Values \\
\hline Method (Sensorial) & 1 \\
\hline Expected criteria (5) & 1 \\
\hline $\begin{array}{l}\text { Activity Status (Task ompleted, } \\
\text { Task Not Completed) }\end{array}$ & 2 \\
\hline $\begin{array}{l}\text { Time (Very fast, Normal, } \\
\text { Satisfactory) }\end{array}$ & 3 \\
\hline No of Criteria $(>=4,3,<=2)$ & 3 \\
\hline Row $=1 \times 1 \times 2 \times 3 \times 3=18$ & \\
\hline
\end{tabular}

The Rule column (column 1) shows the names of the rules which will be constructed (A1 through A4). The Method, Expected Criteria, Activity Status, Time and Number of Criteria columns are the conditions for the rule, with all possible values. The Child Development Analysis column is the outcome generated from the combinations of 
values of the conditions. It is divided into two parts: Accomplishment and Action. The possible values for Accomplishment and Action were obtained from the literature review of the evaluation of Montessori performance. Table 4 shows all of the Set 1 Rules as constructed from the decision table.

\section{TABLE 4: SET 1 RULES}

\begin{tabular}{|c|c|}
\hline $\begin{array}{l}\text { Sample rule for } \\
\text { choosing } \\
\text { criteria }\end{array}$ & $\begin{array}{l}\text { IF method = Sensorial } \\
\text { THEN Expected_criteria = Independence, Confidence, } \\
\text { Intrinsic Motivation, Ability to Handle External } \\
\text { Authority, Academic Achievement } \\
\text { AND No_of_criteria }=5\end{array}$ \\
\hline Rule A1 & $\begin{array}{l}\text { IF activity_status }=\text { Task Completed } \\
\text { AND time accomplished is Fast } \\
\text { AND number_of_criteria }>=4 \\
\text { THEN accomplishment }=\text { Exemplary } \\
\text { AND action = Proceed to next module } \\
\\
\text { IF activity_status = Task Completed } \\
\text { AND time accomplished is Satisfactory } \\
\text { AND number_of_criteria }>=4 \\
\text { THEN accomplishment }=\text { Mastery } \\
\text { AND action = Proceed to next module } \\
\text { IF activity_status = Task Completed } \\
\text { AND time accomplished is Normal } \\
\text { AND number_of_criteria }>=4 \\
\text { THEN accomplishment }=\text { Good } \\
\text { AND action = Proceed to next module }\end{array}$ \\
\hline Rule A2 & $\begin{array}{l}\text { IF activity_status = Task Completed } \\
\text { AND time accomplished is Fast } \\
\text { AND number_of_criteria =3 } \\
\text { THEN accomplishment = Exemplary } \\
\text { AND action = Proceed to next part of the method } \\
\text { IF activity_status = Task Completed } \\
\text { AND time accomplished is Normal } \\
\text { AND number_of_criteria =3 } \\
\text { THEN accomplishment = Mastery } \\
\text { AND action = Proceed to next part of the method } \\
\text { IF activity_status = Task Completed } \\
\text { AND time accomplished is Satisfactory } \\
\text { AND number_of_criteria =3 } \\
\text { THEN accomplishment = Good } \\
\text { AND action = Proceed to next part of the method }\end{array}$ \\
\hline Rule A3 & $\begin{array}{l}\text { IF activity_status = Task Completed } \\
\text { AND time accomplished is Fast } \\
\text { AND number_of_criteria }<=2 \\
\text { THEN accomplishment }=\text { Exemplary } \\
\text { AND action = Proceed to next material } \\
\\
\text { IF activity_status = Task Completed } \\
\text { AND time accomplished is Normal } \\
\text { AND number_of_criteria }<=2 \\
\text { THEN accomplishment = Mastery } \\
\text { AND action = Proceed to next material } \\
\text { IF activity_status = Task Completed } \\
\text { AND time accomplished is Satisfactory } \\
\text { AND number_of_criteria }<=2 \\
\text { THEN accomplishment }=\text { Good } \\
\text { AND action = Proceed to next material }\end{array}$ \\
\hline Rule A4 & $\begin{array}{l}\text { Rule A4 is required for the activity_status with the value } \\
\text { of 'Task Not Completed'. For simpler rule, conclusions } \\
\text { are grouped in a different set. The conclusions are } \\
\text { identified in Set } 3 \text { rules. }\end{array}$ \\
\hline
\end{tabular}

Rule A4 covers activities with a status of 'Task Not Completed'. For simplification, these conclusions are grouped as separate Set 3 rules.

\section{Step 6: Construct the User Interface}

Once the rules are established, the user interface prototype for the Child Analysis Module is designed. This consists of a set of questions that teachers must answer in order to generate the analysis based on the method chosen for a particular child. The first step is to construct the questions that relate to the rules in the KBS. The questions are designed to be easily understood by the users, in this case principals and teachers. Figure 6 shows a prototype of the user interface.

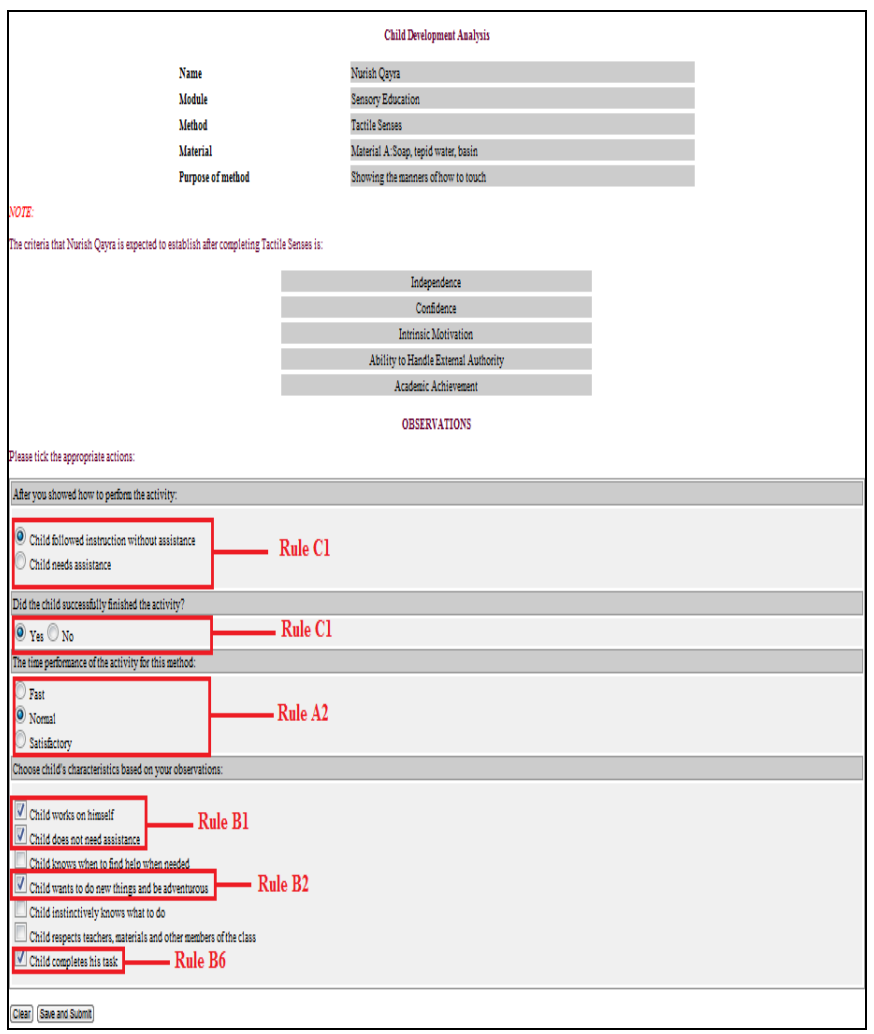

Figure 6: Prototype of a User Interface for Child Development Analysis

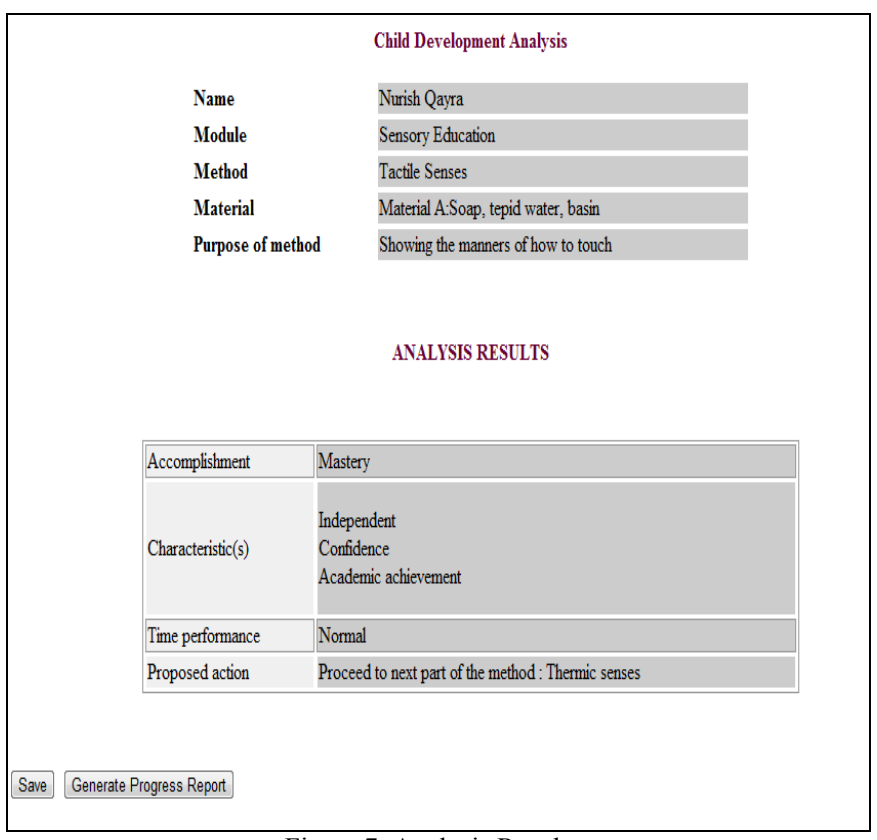

Figure 7: Analysis Results 
TABle 3: DeCision TABLE FOR SET 1 Rules

\begin{tabular}{|c|c|c|c|c|c|c|c|}
\hline Rule & Method & $\begin{array}{l}\text { Expected } \\
\text { Criteria }\end{array}$ & $\begin{array}{l}\text { Activity } \\
\text { Status }\end{array}$ & Time & $\begin{array}{l}\text { No of } \\
\text { criteria }\end{array}$ & $\begin{array}{l}\text { Child Development } \\
\text { Analysis (Accomplishment) }\end{array}$ & $\begin{array}{l}\text { Child Development Analysis } \\
\text { (Action) }\end{array}$ \\
\hline \multirow[t]{3}{*}{ A1 } & Sensorial & 5 Criteria & $\begin{array}{l}\text { Task } \\
\text { Completed }\end{array}$ & Fast & $>=4$ & Exemplary & Proceed to next module \\
\hline & Sensorial & 5 Criteria & $\begin{array}{l}\text { Task } \\
\text { Completed }\end{array}$ & Normal & $>=4$ & Mastery & Proceed to next module \\
\hline & Sensorial & 5 Criteria & $\begin{array}{l}\text { Task } \\
\text { Completed }\end{array}$ & Satisfactory & $>=4$ & Good & Proceed to next module \\
\hline \multirow[t]{3}{*}{ A2 } & Sensorial & 5 Criteria & $\begin{array}{l}\text { Task } \\
\text { Completed }\end{array}$ & Fast & 3 & Exemplary & Proceed to next part of the method \\
\hline & Sensorial & 5 Criteria & $\begin{array}{l}\text { Task } \\
\text { Completed }\end{array}$ & Normal & 3 & Mastery & Proceed to next part of the method \\
\hline & Sensorial & 5 Criteria & $\begin{array}{l}\text { Task } \\
\text { Completed }\end{array}$ & Satisfactory & 3 & Good & Proceed to next part of the method \\
\hline \multirow[t]{3}{*}{ A3 } & Sensorial & 5 Criteria & $\begin{array}{l}\text { Task } \\
\text { Completed }\end{array}$ & Fast & $<=2$ & Exemplary & Proceed to next material \\
\hline & Sensorial & 5 Criteria & $\begin{array}{l}\text { Task } \\
\text { Completed } \\
\end{array}$ & Normal & $<=2$ & Mastery & Proceed to next material \\
\hline & Sensorial & 5 Criteria & $\begin{array}{l}\text { Task } \\
\text { Completed }\end{array}$ & Satisfactory & $<=2$ & Good & Proceed to next material \\
\hline \multirow[t]{9}{*}{ A4 } & Sensorial & 5 Criteria & $\begin{array}{l}\text { Task Not } \\
\text { Completed }\end{array}$ & Fast & $>=4$ & Set 3 & Set 3 \\
\hline & Sensorial & 5 Criteria & $\begin{array}{l}\text { Task Not } \\
\text { Completed }\end{array}$ & Normal & $>=4$ & Set 3 & Set 3 \\
\hline & Sensorial & 5 Criteria & $\begin{array}{l}\text { Task Not } \\
\text { Completed }\end{array}$ & Satisfactory & $>=4$ & Set 3 & Set 3 \\
\hline & Sensorial & 5 Criteria & $\begin{array}{l}\text { Task Not } \\
\text { Completed }\end{array}$ & Fast & 3 & Set 3 & Set 3 \\
\hline & Sensorial & 5 Criteria & $\begin{array}{l}\text { Task Not } \\
\text { Completed }\end{array}$ & Normal & 3 & Set 3 & Set 3 \\
\hline & Sensorial & 5 Criteria & $\begin{array}{l}\text { Task Not } \\
\text { Completed }\end{array}$ & Satisfactory & 3 & Set 3 & Set 3 \\
\hline & Sensorial & 5 Criteria & $\begin{array}{l}\text { Task Not } \\
\text { Completed }\end{array}$ & Fast & $<=2$ & Set 3 & Set 3 \\
\hline & Sensorial & 5 Criteria & $\begin{array}{l}\text { Task Not } \\
\text { Completed }\end{array}$ & Normal & $<=2$ & Set 3 & Set 3 \\
\hline & Sensorial & 5 Criteria & $\begin{array}{l}\text { Task Not } \\
\text { Completed }\end{array}$ & Satisfactory & $<=2$ & - & - \\
\hline
\end{tabular}

As shown in Figure 6, the interface displays the child's name, the module, the method, the material used and the purpose of the method. Next, it lists the criteria that the child is expected to achieve. The criteria depend on the Montessori method chosen. Finally, the interface lists the questions that will be used to generate the analysis.

The red boxes in Figure 6 group the questions by the rule involved for each of them. The teacher can click 'Clear' to undo all the answers or 'Save and Submit' to view the analysis results. When 'Save and Submit' is clicked, the analysis based on the questions as answered by the teacher is displayed, as shown in Figure 7.

In Figure 7, the analysis is broken down into four elements: accomplishment, characteristics, time performance and proposed action. The teacher can either save the analysis into the system or generate a progress report. If the analysis is saved, the system will acknowledge whether the method is being stored as 'In Progress' or 'Completed' according to the value in the Proposed Action field. If the Proposed Action is 'Proceed to next module' or 'Proceed to next part of the method', then the system will save the method as 'Completed'. If the Proposed Action is 'Proceed to next material', the system will save the method as 'In Progress'.

\section{Phase 4: Summary and Discussion}

Since the Montessori approach relies on teachers' observations to analyze a child's performance, the criteria of the teachers' observations should be updated from time to time. The database of the KBS will thus be improved parallel with the ongoing study of Montessori methods, philosophies and techniques. As a result, the information needed to generate the If-Then Rules will increase and, ideally, the questions asked to transform the information into results will be improved. It is hoped that the development of this prototype will become the foundation of a more advanced and comprehensive system for Child Development Analysis. Future expansion of the KBS is possible, such as using backward-chaining rule-based reasoning whereby a child's characteristics and personality can be obtained through rule induction from the analysis of the child's performance. Different types of reasoning can also be applied, such as case-based reasoning, frame, blackboard and decision tree reasoning [3].

\section{CONCLUSIONS}

Rule-based reasoning was chosen for this research in the application of KBS to Montessori student evaluation because the field of Montessori knowledge is well defined and has been separated and categorized by its methods, with each method having its own theory, materials and philosophy. It is also suitable because of its ability to ask questions to solve problems. Even though the problem might seem too simple for the knowledge based technique, this techniques still has 
its advantages and is worth the investment. Since there is a great deal of specific knowledge involved in Montessori methods, the use of rule-based reasoning will make knowledge encoding easier and quicker [9]. If conventional rules are applied, rule development will take longer, carry an increased risk of error, and compromise the quality of the system. In addition, with the application of rule-based reasoning, the manipulation of rules will be more flexible and the number of logical rules can be reduced [9]. The rulebased reasoning approach uses forward chaining since it examines the IF clauses and searches for solutions by working from data toward the solution.

\section{ACKNOWLEDGMENT}

The authors are grateful to the School of Computer Sciences of Universiti Sains Malaysia (USM) for their support in the form of APEX Incentive Grant and dedication in producing quality research papers. A special thank you to Puan Ladyana Zoraya Abdullah for taking her time to explain and share her knowledge about Montessori and eventually agreeing to become advisor.

\section{REFERENCES}

[1] McCarthy, J. (2007). What Is Artificial Intelligence?, from http://www-formal.stanford.edu/jmc/whatisai/whatisai.html

[2] Dutta, S. (1993). Knowledge Processing \& Applied Artificial Intelligence. Great Britain: Butterworth Heinemann.

[3] Mockler, R. J., \& Dologite, D. G. (1992). Knowledge Based Systems: An Introduction to Expert Systems. New York: Macmillan Publishing Company.

[4] Chi, R. T. H., \& Kiang, M. Y. (1993). Reasoning by Coordination: an Integration of Case-Based and Rule-Based Reasoning Systems. 6.

[5] Scott-Little, C. (2011). Assessing Kindergarten Children: What School Systems Need to Know. Retrieved January 2011, from http://www.tats.ucf.edu/docs/rdakcg.pdf

[6] Olaf, M. (2011). Montessori Materials \& Learning Environments for the Home and the School 2010, from http://www.montessori.edu

[7] Strachan, D. (2011). Montessori Assessment. http://www.soaringwings.org/2011/02/09/montessori-assessment/

[8] Bourne, L. (2008). How to Evaluate the Progress of a Montessori Child. http://www.blog.montessoriforeveryone.com/how-to-evaluatethe-progress-of-a-montessori-child.html

[9] Merrit, D. (2004). Best Practices for Rule-Based Application Development. The Architecture Journal, 24. 